\title{
The manufacturability and compression properties of the Schwarz Diamond type Ti6Al4V cellular lattice fabricated by selective laser melting
}

\author{
Joanna Maszybrocka ${ }^{1} \cdot$ Bartosz Gapiński ${ }^{2} \cdot$ Michał Dworak $^{1} \cdot$ Grzegorz Skrabalak $^{3} \cdot$ Andrzej Stwora $^{3}$
}

Received: 9 November 2018 / Accepted: 16 September 2019 / Published online: 12 November 2019

(C) The Author(s) 2019

\begin{abstract}
Selective laser melting technology makes it possible to produce 3D cellular lattice structures with controlled porosity. The paper reflects to machining and examination of structures with predefined distribution, shape and size of the pores. In the study, the porous structures of Ti6A14V were investigated. The tests were carried out using structures of spatial architecture of Schwarz D TPMS geometry with a total porosity of $60 \%$ and $80 \%$ and various pore sizes. Dimensional accuracy of additively manufactured structures was measured in relation to the 3D model. Geometry of the final structure differed from the CAD model in the range $\pm 0.3 \mathrm{~mm}$. The surface morphology and porosity of the solid struts were also checked. The mechanical properties of the structures were determined in a static compression test.
\end{abstract}

Keywords Cellular lattice structures $\cdot$ Selective laser melting $\cdot$ Additive manufacturing $\cdot$ Mechanical properties

\section{Introduction}

Cellular materials such as foams and metallic sponges have been developed for many years $[1,2]$. Due to the specific spatial structure, they have unique properties, what opens up a wide field of practical application for these type materials [3-5]. These structures find its application in automotive and aviation industry, as they can significantly reduce weight of the component, not influencing its performance. Application of foams and metallic sponges in airplane translates into reduction of fuel consumption and consequently can affect the reduction of pollutant emissions [6-8].

Discussed structures are characterized not only by good/controllable mechanical properties, but they are able also to suppress sounds. This phenomena makes this group of

Joanna Maszybrocka

joanna.maszybrocka@us.edu.pl

1 Institute of Materials Engineering, University of Silesia, ul. 75 Pułku Piechoty 1A, 41-500 Chorzów, Poland

2 Institute of Mechanical Technology, Poznań University of Technology, ul. Piotrowo 3, 60-965 Poznań, Poland

3 Institute of Advanced Manufacturing Technology, ul. Wrocławska 37A, 30-011 Kraków, Poland materials suitable for production of various elements reducing the noise level, e.g., in pneumatic systems. In this case, it is essential to achieve compromise between the noise reduction and adequate flow rate of medium through the porous structure. It depends, among others, on airflow resistance, porosity, and pore morphology $[9,10]$. On the other hand, high degree of developed interfacial area ratio makes it possible to apply cellular metals with an open structure as an alternative to the classical porous and structural fillings in various types of heat exchangers, heat regenerators, catalytic reactors, or filtration apparatus $[11,12]$.

Porous structures, especially made of biocompatible materials, are used in regenerative medicine, i.e., implants with porous structure allow better osseointegration of the bone tissue, comparing to standard material. Thanks to this, it is possible to create a stable implant-tissue connection without the necessity of using bone cement. Properly designed structure of the porous implant allows better adaptation to the biomechanical conditions in the tissue implant system, which reduces the risk of implant failure [13-16].

The structure of metal foams is usually described as a geometrically disordered arrangement of pores in a metal matrix. The mentioned randomness is a consequence of classical methods of producing cellular structures such as powder metallurgy, chemical or electrochemical deposition, vacuum evaporation, and liquid-phase methods [2]. The random 
distribution and shape of the pores during production with the abovementioned methods cause difficulties in prediction of behavior of such materials (e.g., the mechanisms of deformation or destruction of such material) or even make such prediction impossible. An alternative to traditional methods of producing metallic porous materials is methods of additive manufacturing and among them selective laser melting (SLM) technique [17-20].

SLM process offers the possibility of producing complex geometric shapes based on a three-dimensional CAD model. This allows precise control over not only the geometry of the product, but also shape, size, and distribution of the pores in the proposed structure. This creates promising perspectives for the design and manufacture of metallic porous materials which geometries will be precisely tailored to specific requirements.

Important role in the whole process is the preparation of a three-dimensional model of a porous structure, which will be produced. There are many approaches for scaffold design. Typically, an elementary cell model is developed in CAD programs with the help of several basic objects (e.g., sphere, cylinder, cube) which are usually bounded by logical operations. Then, the elementary cell is reproduced in threedimensional space [21-23]. Recently, much attention has been devoted to the ability of generating cellular structures based on mathematical formulas with described triply periodic minimal surfaces (TPMS) [24-27].

Minimal surfaces are defined as surfaces with zero mean curvature at all points. Triply periodic minimal surfaces (TPMS) are minimal surfaces which are periodic in three independent directions [28]. They divide space into two intertwined labyrinth domains with smooth joints and curvatures. There are several ways for generating the coordinates of TPMS. The parametric TPMS representation is known as Enneper-Weierstrass formula. It was shown that basing on this formula, the exact computation of the Cartesian coordinates of the fundamental patch of several TPMS surfaces: G "gyroid," D “diamond," and P "primitive" was possible [29-31]. TPMS can be also approximated by the periodic nodal surface [32]. Based on simple trigonometric functions, with approximate TPMS, a mesh surface can be easily generated. The selection of the appropriate function and adjustment of its parameters enable control of the shape, size, and distribution of pores and the total porosity of the cellular lattice model in a wide ranges [33].

The complex topology of TPMS and, as a result, the unique properties makes them useful to design cellular lattice structures for various practical applications. Due to their interconnectivity, tortuosity, and high surface-to-volume ratio, the topology of TPMS might be successfully applied for designing of scaffolds for bone tissue engineering [34-37].

Recent studies have shown that cellular lattice structures can be successfully manufactured using SLM process from
Ti6Al4V powder. Most of the presented investigations focus on manufacturability of cellular lattices and the influence of unit cell geometry and relative density on the mechanical response of cellular lattice. Published studies concern regular lattice-based geometries and only some concern the TPMSbased geometries. For example, Zaharin et al. [38] investigated the gyroid scaffold with pore sizes ranging from 300 to $600 \mu \mathrm{m}$ and total porosity of 70.2-81.1\%. The compression strength was in the range 23-11.5 MPa. Yan et al. [39] compared mechanical properties of SLM-manufactured gyroid and diamond TPMS with high porosity of 80-95\% and with pore size ranging from 560 to $1600 \mu \mathrm{m}$ and from 480 to 1450 $\mu \mathrm{m}$. The compression strength was respectively in the range 6.5-81.3 MPa and 4.6-69.2 MPa. Kadkhodapour et al. [40] presented structure-property relations for Ti6Al4V scaffolds based on F-RD and I-WP unit cell. Cellular lattices were manufactured at different volume fractions: $30 \%$ and $45 \%$ for I-WP-based cellular lattice and $45 \%$ for F-RD-based cellular lattice. The compression strength for I-WP was found to be by far higher than the F-RD structure at the same $45 \%$ volume fraction: $218 \mathrm{MPa}$ against $145 \mathrm{MPa}$. Chunze Yan et al. [41] presented compression strength results for TPMS lattices with gyroid unit cell (85\% volume fractions) in the asbuilt condition and after heat treatment. The compressive strength decreases from 47.6 to $36.9 \mathrm{MPa}$ after heat treatment in $1050{ }^{\circ} \mathrm{C}$. Bearing in mind the presented research, it can be seen that the authors focused on the Ti6A14V, TPMS cellular lattice based on gyroid unit cell. However, there are various types of unit cell geometries in the TPMS family; therefore, it is advisable to explore the structure properties for other geometries of the single unit cell.

This study presented an investigation of the effects of unit cell size on the manufacturability and mechanical performance of Ti6Al4V diamond Schwarz-type cellular lattice structures processed by selective laser melting.

\section{Methodology}

\subsection{Modeling and computer-aided design of the cellular lattice}

For performance of the tests, the models of Schwarz' diamond (D) surface, described by Eq. 1, were prepared in Matlab software:

$$
\begin{aligned}
& k_{1} \cdot(\sin (n \cdot x) \cdot \sin (n \cdot y) \cdot \sin (n \cdot z)+\sin (n \cdot x) \cdot \cos (n \cdot y) \cdot \cos (n \cdot z)(1) \\
& +\cos (n \cdot x) \cdot \sin (n \cdot y) \cdot \cos (n \cdot z)+\cos (n \cdot x) \cdot \cos (n \cdot y) \cdot \sin (n \cdot z)) \\
& \quad+k_{2}(\cos (n \cdot 4 \cdot x) \cos (n \cdot 4 \cdot y) \cos (n \cdot 4 \cdot z))+k_{3}=0
\end{aligned}
$$


Parameters $k_{1}, k_{2}$, and $k_{3}$ in Eq. 1 allowed to control the porosity of cell element and the same porosity of the final model. They were chosen to achieve the porosity of the structure $V_{v}=80 \%$ and $60 \%$. The volume ratio is defined as the ratio of the volume of pores to the total volume of the surrounding area:

$V_{v}=\frac{V_{\text {pores }}}{V_{\text {tot }}}$

where

$\mathrm{V}_{\text {pores }}$ the volume of pores

$\mathrm{V}_{\text {tot }}$ the total volume of the surrounding area

Parameter $n$ in Eq. 1 allows controlling the size of the basic unit cell. It was assumed that the area of modeling will constitute a cube with dimensions of $15 \times 15 \times 15 \mathrm{~mm}$. The threedimensional mesh as a set of coordinates of the vertices and the set of elements that define the topology of the grid has been exported to .stl format. Models prepared for SLM process are shown in Fig. 1.

\subsection{Material and processing parameters}

Structures presented in Fig. 1 were manufactured of Renishaw's Ti6Al4V powder, of chemical composition presented in Table 1. The powder grains had spherical shape and their surface was smooth. This indicates a good flowability [42]. Powder used for investigations was of average size of grain $-40 \mu \mathrm{m}$ ( $80 \%$ of grains shall be in the range $35-45 \mu \mathrm{m}$ and $20 \%$ within the range 10-80 $\mu \mathrm{m}$ ) (Fig. 2).

For manufacturing of the presented 3D models, the selective laser melting machine Renishaw AM 250 was used. The system is equipped with a 400-W fiber laser Yb-fiber $(\lambda=1064 \mathrm{~nm})$. Parameters of the SLM process are presented in Table 2.

\subsection{Equipment used for structure properties analysis}

Prepared samples of lattice structures were subjects for further analysis including: X-ray tomography, SEM analysis, and testing of mechanical properties.

Tomographic studies were carried out on the measuring Xray tomograph GE vjtomejx s 240. The device is equipped with two X-ray sources - the first one is a reflection target with a maximum power of $320 \mathrm{~W}$, and the second one is a transmission target with maximum power of $15 \mathrm{~W}$. Both Xray sources were used for the investigation - the reflection target with micro focus allowed examining the entire structure of Ti6A14V made using 3D printing. These studies were carried out in macroscale for the magnification $\times 2.4$ and a voxel size of $83 \mu \mathrm{m}$. The parameters of the measured object are determined by the spatial resolution in the gray scale. Thanks to the sub-voxel resolution, it is possible to determine the accuracy of the surface description even $10 \times$ more accurately than the size of the voxel [43]. This smoothes the edges and its values are limited by the image noise and the spread of the gray scale.

SEM microscopic analysis of samples was performed using JEOL JEM-3010 scanning microscope. To reflect the three-dimensional nature of the structure, observations were carried out at an inclined measuring table (about 25 degrees).

The static compression tests were carried out using a universal testing machine Instron 5982 equipped with $100 \mathrm{kN}$ load cell, with a constant crosshead speed of $0.1 \mathrm{~mm} / \mathrm{min}$. The tests were carried out at room temperature. During the measurement, compression stress versus compression strain data was recorded. The compression strain data was recorded with an Instron 2663 video extensometer. Stress was computed from the load and cross-sectional area of the sample (about $15 \times 15 \mathrm{~mm}^{2}$ ). After the test, the first maximum compressive strength and elastic gradient was determined. It was assumed that the first maximum compressive strength corresponds to the first local maximum in the stress-strain curve, and elastic gradient is the gradient of the straight line determined within the linear deformation region at the beginning of the compressive stress-strain curve [44, 45].

Compressive strength of the tested samples was determined as the quotient of the maximum compressive force $F_{\max }$ and the area of the initial cross-section of the sample $S_{0}$ according to the formula:

$\sigma_{s f 1}=\frac{F_{\max }}{S_{0}}$

where

$\sigma_{s f 1} \quad$ compressive strength (first peak on the curve)

$\mathrm{F}_{\max }$ maximum value of compressive force

$S_{0} \quad$ initial cross-section area of the sample

\subsection{FEA simulation}

Investigation of the elastic response of the cellular lattice structures was performed in Abaqus/Standard 2016 from Dassault Systemes, Vélizy-Villacoublay, France. The cellular lattice model was placed between two rigid plates (Fig. 3). All degrees of freedom of the bottom plate were fixed. Vertical downward displacement $0.05 \mathrm{~mm}$ was applied to the upper surface to simulate the load. Ten-node tetrahedral element (C3D10) was used for meshing cellular lattice. Mesh convergence analysis was carried out for each cellular lattice model. For the FEA, the material properties were assumed to be uniform and isotropic (Young's modulus E $=110 \mathrm{GPa}$ and Poisson ratio $v=0.3$ ). The numerical simulations were performed by PLGrid Infrastructure (Prometheus, ACC Cyfronet, AGH) (http://www.plgrid.pl/). 


\begin{tabular}{|c|c|c|c|}
\hline \multicolumn{4}{|c|}{$\mathrm{Vv}=80 \%$} \\
\hline Lattice name & D801 & $\mathrm{D} 802$ & D803 \\
\hline \multicolumn{4}{|l|}{ Lattice model } \\
\hline $\begin{array}{l}\text { Number of basic } \\
\text { cell unit }\end{array}$ & 4 & 6 & 12 \\
\hline $\begin{array}{l}\text { Total number of } \\
\text { unit cell }\end{array}$ & 64 & 216 & 1728 \\
\hline $\begin{array}{l}\text { Surface area } \\
{\left[\mathrm{cm}^{2}\right]}\end{array}$ & 29,6 & 54,01 & 105,56 \\
\hline $\begin{array}{l}\text { Surface to } \\
\text { volume ratio }\end{array}$ & 10,9 & 16,0 & 31,3 \\
\hline \multicolumn{4}{|c|}{$V v=60 \%$} \\
\hline Lattice name & D601 & D602 & D603 \\
\hline \multicolumn{4}{|l|}{ Lattice model } \\
\hline $\begin{array}{l}\text { Number of basic } \\
\text { cell unit }\end{array}$ & 4 & 6 & 12 \\
\hline $\begin{array}{l}\text { Total number of } \\
\text { unit cell }\end{array}$ & 64 & 216 & 1728 \\
\hline $\begin{array}{l}\text { Surface area } \\
{\left[\mathrm{cm}^{2}\right]}\end{array}$ & 29,6 & 44,4 & 85,1 \\
\hline $\begin{array}{l}\text { Surface to } \\
\text { volume ratio }\end{array}$ & 8,8 & 13,4 & 25,2 \\
\hline
\end{tabular}

Fig. 1 Visualization of the cellular lattice models and their basic parameters

Table 1. Chemical composition of the used Ti6Al4V powder

\begin{tabular}{ll}
\hline Element & Mass $(\%)$ \\
\hline Titanium & Balance \\
Aluminum & 5.50 to 6.50 \\
Vanadium & 3.50 to 4.50 \\
Iron & $\leq 0.25$ \\
Oxygen & $\leq 0.13$ \\
Carbon & $\leq 0.08$ \\
Nitrogen & $\leq 0.05$ \\
Hydrogen & $\leq 0.012$ \\
Yttrium & $\leq 0.005$ \\
Residuals & $\leq 0.10$ each, $\leq 0.40$ total \\
\hline
\end{tabular}

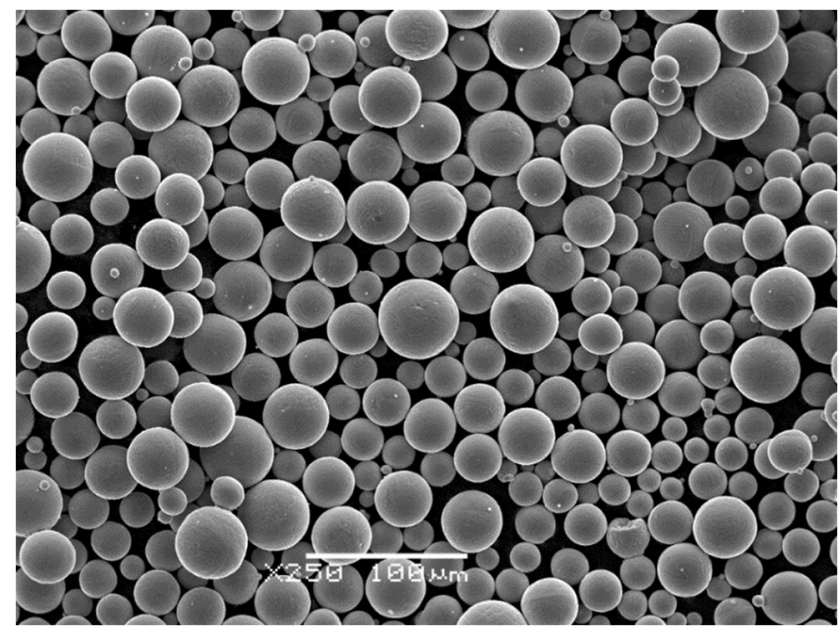

Fig. 2 Ti6Al4V powders 
Table 2. Technological parameters of the SLM process used for Ti6Al4V powder on Renishaw AM 250 (400W) machine

\begin{tabular}{lllll}
\hline Laser power & Scan speed & Point distance & Layer thickness & Scan strategy \\
\hline $400 \mathrm{~W}$ & $150 \mathrm{~mm} / \mathrm{s}$ & $75 \mu \mathrm{m}$ & $50 \mu \mathrm{m}$ & Meander \\
\hline
\end{tabular}

Elastic modulus of the cellular lattice structure was obtained from the equation:

$E_{\text {latt. }}=\frac{F \cdot h}{A \cdot u}$

where

$F$ total reaction force at the top surface of the structure,

$h$ original height of the lattice,

A cross-sectional area of the lattice,

$u$ displacement of the top surface in the loading direction.

\section{Results}

\subsection{Morphology and microstructure of the cellular lattice struts}

Microscopic observations of the struts microstructure (Fig. 4) revealed characteristic features of the Ti6Al4V alloy produced with SLM technique. The microstructure is composed of plate-shaped martensitic phase $\alpha^{\prime}$ with articular morphology (Fig. $4 b$ ) formed from the columnar prior- $\beta$ grains. Elongated or "columnar" grains (Fig. 4a) result from epitaxial solidification during SLM process $[46,47]$. The rapid solidification and cooling rates cause the bcc $\beta$ phase of Ti6Al4V alloy to transform completely into metastable hcp $\alpha^{\prime}$ martensite phase by a diffusionless, shear-type transformation process $[48,49]$.
Figure 5 shows SEM images of the outer surfaces of SLMmanufactured cellular lattice structures. The spatial architecture of the samples seems to fit the CAD model presented in Fig. 1. On the presented outer surface of structures, complex morphology may be observed. It results from the nature of SLM process and the process parameters that were used. Melting process of the Ti6Al4V powder conducted layer by layer with a laser beam causes the inclined struts to show the characteristic for additive manufactured parts staircase effect. Its size depends on the thickness of the layer. On the prepared struts, no interlayer delamination was found. This fact indicates that the consolidation of individual layers during the process was successful. Numerous spherical or partially melted particles are visible on the surface of the struts. Their presence is caused, among others, by the difference in heat transport between powder and solid material, sintering fragments of the struts partially on the loose powder, as well as melting powder particles by the laser beam along the outer contour of the part [50]. Quantification of the characteristic features of the struts was presented by authors in an earlier work [51].

\subsection{Dimensional accuracy of the Ti6Al4V cellular lattice}

Images from the scanning microscope allowed performing qualitative assessment of the struts structure, but only on its several outer layers. Unfortunately, it is not enough, in

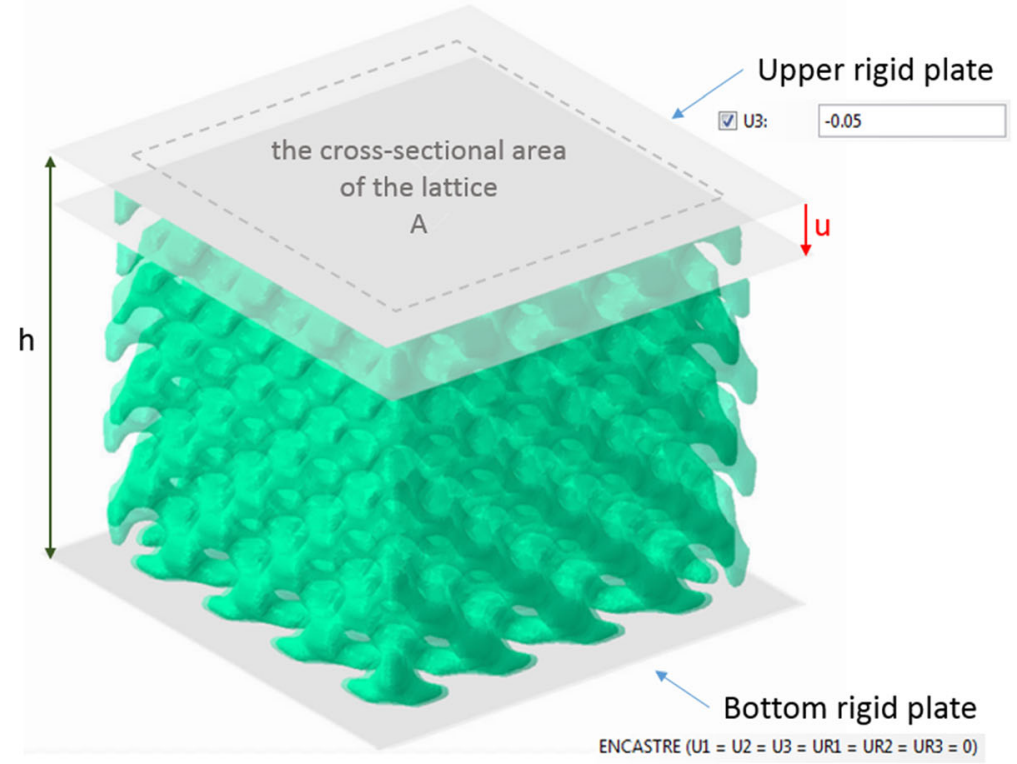

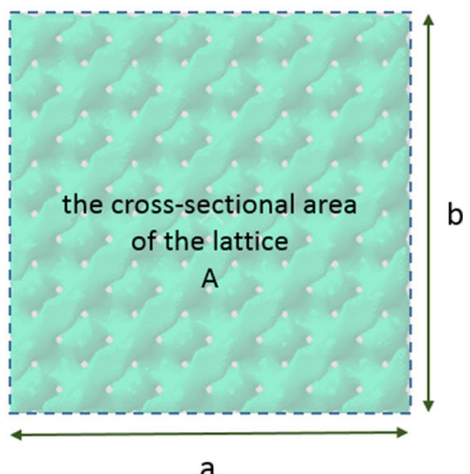

Fig. 3 Applied boundary conditions 
Fig. 4 Optical (a) and scanning electron microscope (b) micrograph of the cross-sectional microstructure of the cellular lattice strut
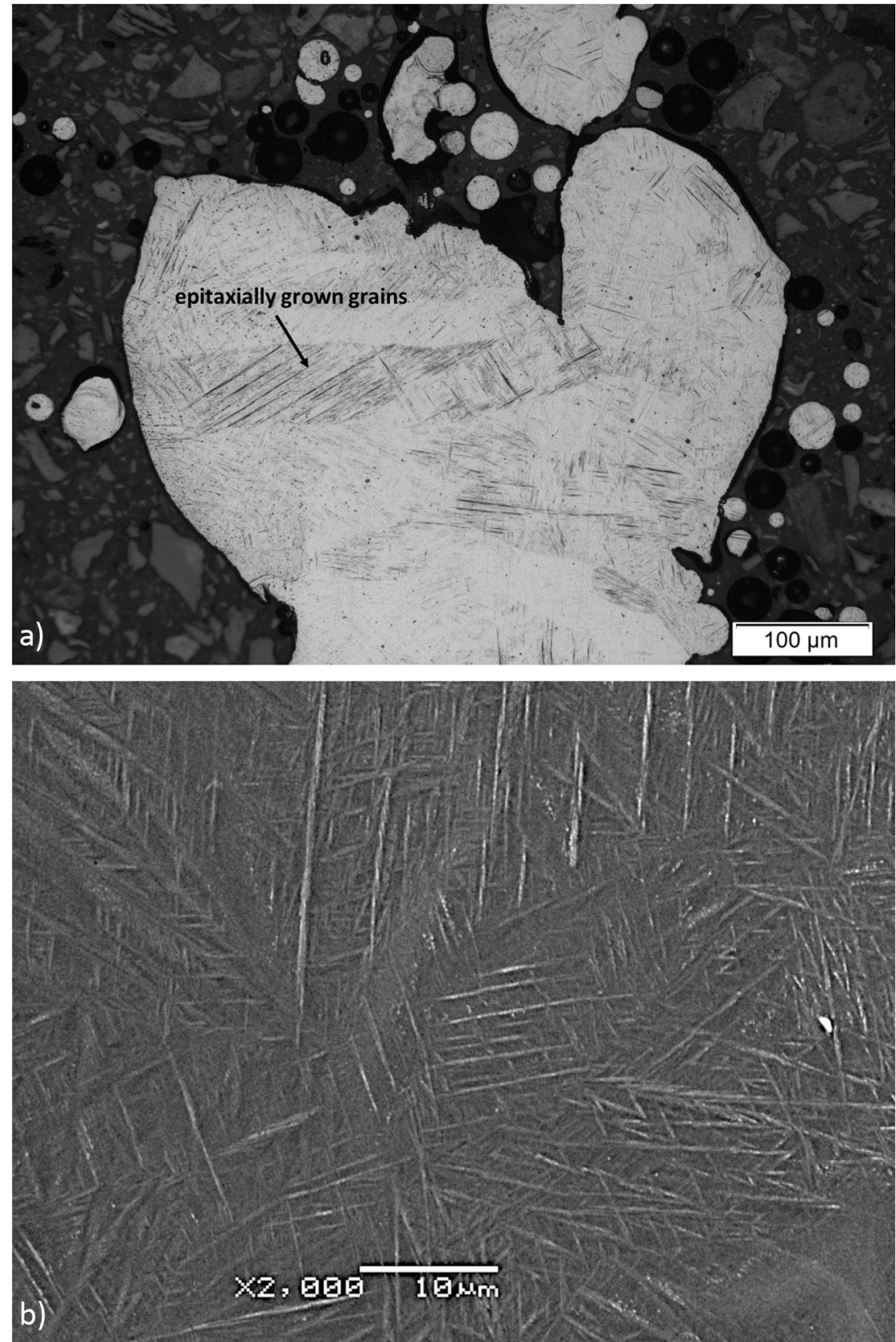

this case, as for the structures of this type, it is important to obtain information about the geometry of the structure in their entire volume. Traditional coordinate measurement techniques (such as CMM) are not applicable for these geometries; therefore, analysis of the geometry accuracy of the manufactured cellular lattice structures was carried out by comparing the model obtained from tomographic examinations with the 3D-CAD model (section 2.1). For geometry analysis GOM Inspect software was used. Results of the comparison are deviation maps, which are presented in Fig. 6. The average deviations for all structures are within the range $+0.3 /-0.15 \mathrm{~mm}$. The largest deviation was observed for the samples D603 and D803.
In their cases, it can be observed that the deviation histogram has a large asymmetry. The largest deviations were recorded in places where spherical Ti6Al4V powders or partially melted agglomerates were attached to the struts surfaces. This confirms earlier conclusions derived from SEM microstructure observations.

Comparing the actual porosity of the samples, estimated from microtomography measurement, and the nominal porosity resulting from the model, it can be concluded that the total porosity of the manufactured samples is lower on average by 4-18\% in relation to the porosity of the CAD model (Table 3 ). The largest difference was observed for samples with the smallest basic unit cell (D803 and D603). 
Fig. 5 Cellular lattice structures as manufactured by SLS. a D601. b D801. c D602. d 802. e D603. f D803
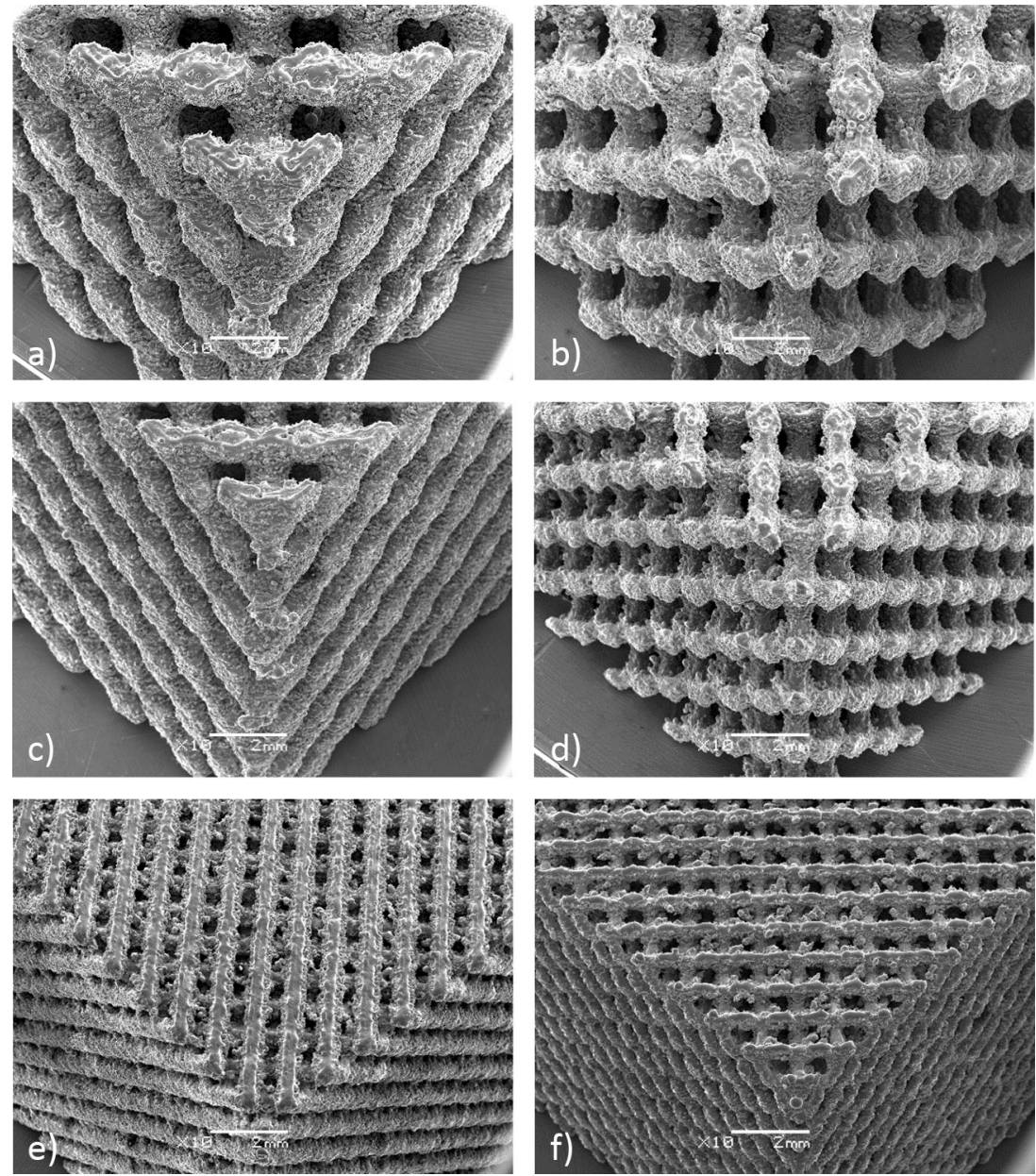

Results of microtomography measurements of the 3D structures revealed that there appear pores in the solid structure of the struts (Fig. 7). The presence of pores in the solid bar structure is an undesirable phenomenon because the pores can degrade the mechanical properties of the entire structure. Their influence on mechanical properties is complicated and depends not only on their number and distribution but also on the shape, size, and spatial orientation. In Fig. 7, there is shown spatial visualization of pore distribution in the samples. However, pores are visible in all of the manufactured cellular lattices; the internal porosity of the struts is relatively small and does not exceed $0.2 \%$ (Table 4 ).

Observed internal porosity on one hand results from the nature of the SLM process and machining parameters, while on the other, it might be also influenced by the specific geometry of the built structures. In case of self-supporting structures, which are these structures, it has been shown that the tendency to the formation of defects during the SLM process is almost negligible [52, 53]. Microtomography allowed fast detection of structure defects. It should be noted that the determined values of the total porosity of the solid struts can be underestimated [54]. It is influenced by the resolution of the measurement itself (minimum size of the measured defect 54 $\mu \mathrm{m})$, and on the other hand, applied defect detection algorithm in the VGStudio software allows to analyze only closed pores. This may explain why in case of structures with the smallest elementary unit cell, no internal defects have been detected.

The authors also measured internal porosity with higher resolution for sample fragments of built structures. Measurements were performed for a $10-\mu \mathrm{m}$-size voxel. This allowed the detection of a number of internal pores with a small volume. Due to their small volume, the total value of porosity in the analyzed fragments increased only by a few percent, which means that the internal porosity of the samples would change only in the range of $0.01-0.02 \%$.

\subsection{Mechanical properties of the cellular lattices}

By analyzing the shape of the samples during compression and the shape of the stress-strain curve, it can be concluded that the samples exhibit a similar of compressive failure modes. On the stress-strain curve, several characteristic areas can be distinguished (Figs. 8, 9). For small deformations, the strain-stress curve has an almost linear shape, which then transforms into a non-linear shape, and the stress increases up to the maximum load-bearing capacity $\left(\sigma_{\mathrm{pk} 1}\right)$. After 
Fig. 6 Dimensional accuracy of the cellular lattices. a D601. b D801. c D602. d D802. e D603. f D803
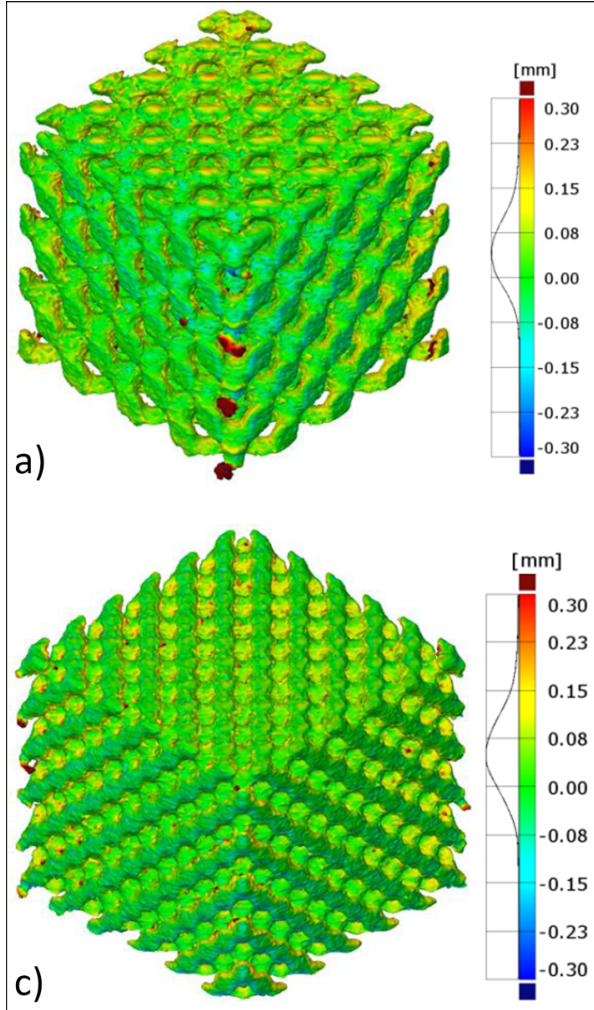

b)
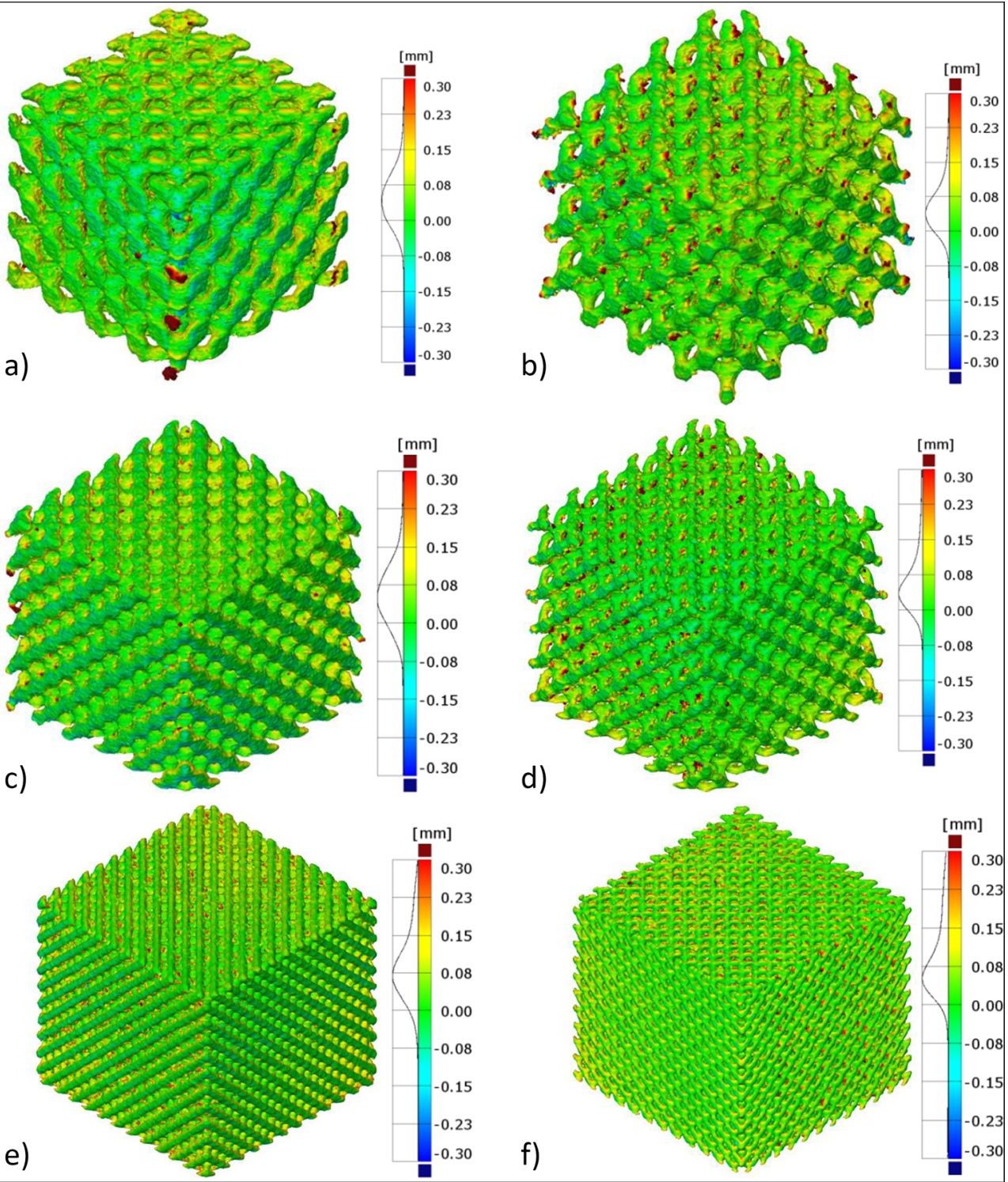

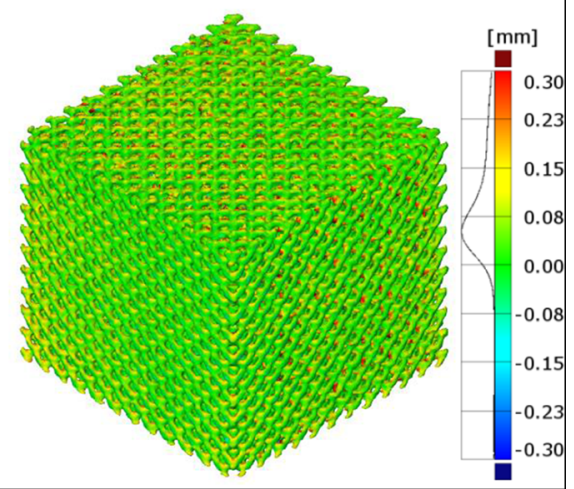

reaching the maximum value of the stress, the curve falls to the stress values characteristic for individual samples $\left(\sigma_{\mathrm{sf} 1}\right)$, then there is a plateau region, in which the deformation increases with a slight increase in stresses, after which stress again increases and decreases, forming series of peaks, which are characteristic for a given structure. The shape of the curve in the form of the peaks series reflects the mechanism of destruction of cellular structures.

Table 3. The real porosity of the samples

\begin{tabular}{lllll}
\hline Sample & $\begin{array}{l}\text { Measured material volume } \\
\text { of the cellular lattice }\left[\mathrm{mm}^{3}\right]\end{array}$ & $\begin{array}{l}\text { Measured porosity } \\
\text { of the cellular lattice [\%] }\end{array}$ & $\begin{array}{l}\text { Porosity of the CAD model } \\
\text { of cellular lattice [\%] }\end{array}$ & $\begin{array}{l}\text { Difference between measured porosity and } \\
\text { theoretical porosity of the structure model [\%] }\end{array}$ \\
\hline D801 & 753.43 & 76.1 & 80 & 3.9 \\
D802 & 799.58 & 74.6 & 80 & 5.4 \\
D803 & 1125 & 64.3 & 80 & 15.7 \\
D601 & 1327.27 & 57.9 & 60 & 2.1 \\
D602 & 1419.63 & 54.9 & 60 & 5.1 \\
D603 & 1838.14 & 41.6 & 60 & 18.4 \\
\hline
\end{tabular}



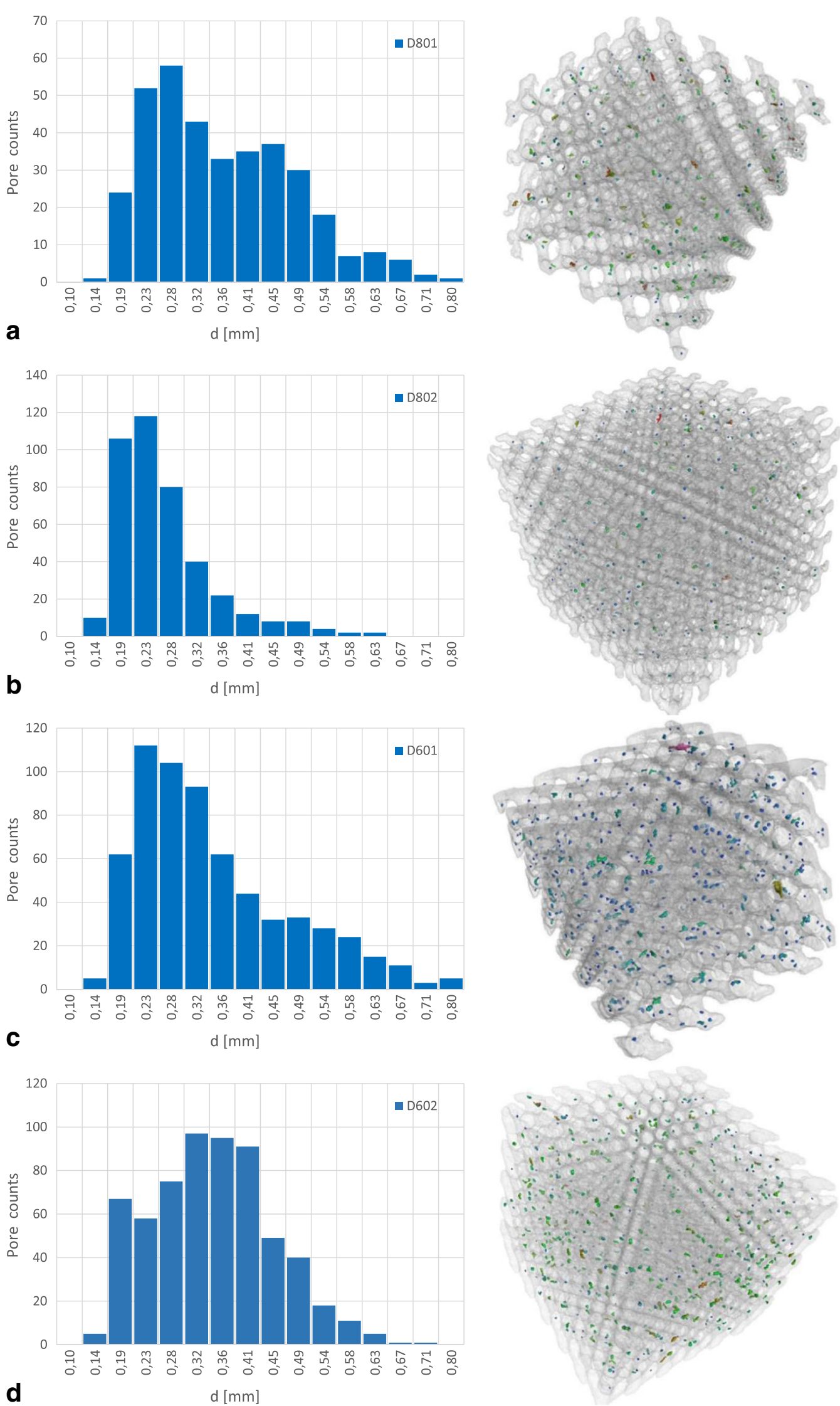

Fig. 7 Pore size distribution and visualization of the internal pores in the struts of the cellular lattice. a D801. b D802. c D601. d 602 
Table 4. Determined parameters of the pores in the strut of the samples

\begin{tabular}{llllll}
\hline Sample & $\mathrm{d}_{\min }$ & $\mathrm{d}_{\max }$ & $\mathrm{d}_{\text {avg }}$ & $\begin{array}{l}\text { Volume of internal } \\
\text { pores }\left[\mathrm{mm}^{3}\right]\end{array}$ & $\begin{array}{l}\text { Internal porosity of } \\
\text { the struts [\%] }\end{array}$ \\
\hline $\mathrm{D} 801$ & 0.13 & 0.78 & $0.34 \pm 0.12$ & 1.53 & 0.20 \\
$\mathrm{D} 802$ & 0.12 & 0.61 & $0.24 \pm 0.08$ & 0.97 & 0.12 \\
D601 & 0.12 & 1.77 & $0.33 \pm 0.14$ & 2.76 & 0.21 \\
D602 & 0.13 & 0.69 & $0.32 \pm 0.10$ & 2.30 & 0.16 \\
\hline
\end{tabular}

Values of peak compressive strength $\left(\sigma_{\mathrm{pk} 1}\right)$, collapse strength $\left(\sigma_{\mathrm{sf}}\right)$, and corresponding deformation $\varepsilon_{\mathrm{pk} 1}, \varepsilon_{\mathrm{sf}}$ are presented in Table 5 .

The highest compressive strength $\left(\sigma_{\mathrm{pk} 1}\right.$ about $\left.177 \mathrm{MPa}\right)$ has a series of samples, for which the total volume of pores was $60 \%$. This series is also characterized by the largest modulus of elasticity of approx. $10.7 \mathrm{GPa}$. The samples for which the total volume of pores was $80 \%$ were characterized by compressive strength $\left(\sigma_{\mathrm{pk} 1}\right)$ at $61 \mathrm{MPa}$, and their average modulus of elasticity was $3.5 \mathrm{GPa}$. In a series of samples with a porosity of $60 \%$ and $80 \%$, it can be seen that the modulus of elasticity increases with increasing number of basic unit cells in the entire cellular structure. This is probably related to the "size effect" of $3 \mathrm{~d}$ periodic cellular structures.

When analyzing the shape of the curves, it can be concluded that the susceptibility of the examined cellular structures to the plastic strain is varied. In case of the series of samples with a porosity $V_{v}=80 \%$, the strain $\varepsilon_{\mathrm{pk} 1}$ at the maximum stress $\sigma_{\mathrm{pk} 1}$ is the highest for sample D801 $\left(\varepsilon_{\mathrm{pk} 1-801}=8.4 \%\right)$ and the lowest for D803 $\left(\varepsilon_{\mathrm{pk} 1-803}=4.5 \%\right)$. For the series of samples with porosity $V_{v}=60 \%$, this relation is also maintained, and the values are, respectively, for the sample D601 $\left(\varepsilon_{\mathrm{pk} 1-601}=\right.$ $7.7 \%)$ and for the sample $603\left(\varepsilon_{\mathrm{pk} 1-603}=6.3 \%\right)$. Bearing in mind that $\sigma_{\mathrm{pk} 1}$ for the series of samples with the same porosity has a similar value, it can be concluded that the greatest susceptibility to plastic deformation is exhibited by structures with the largest unit cell size.
Work to failure $\mathrm{W}_{\mathrm{pk} 1}$ for all the samples is collected in Table 5. It was determined as the area under the first peak up to the deformation of $\varepsilon_{\text {sfl }}$ corresponding to $\sigma_{\text {sfl }}$. For samples with a porosity of $80 \%, \mathrm{~W}_{\mathrm{pk} 1}$ varies from $14 \mathrm{~J}$ for the sample D801 to about $7 \mathrm{~J}$ for the sample D803, while for samples with porosity of $60 \%$, these values vary from 40 to $29 \mathrm{~J}$ for samples D601 and D603, respectively. The largest amount of energy required to cause failure of the sample was found for the sample series with the total porosity $V_{v}=60 \%$. This value decreases with decreasing basic unit cell.

Ratio of the first maximum stress $\left(\sigma_{\mathrm{pk} 1}\right)$ to the plateau stress $\left(\sigma_{\mathrm{sfl}}\right)$ depends both on porosity of the structure and on the size of the basic unit cell. The largest size quotient 14.3 was found for the sample D801, while the smallest value 2 was calculated for sample D603.

After densification of the first damaged layer up to 80-90\% of the initial crushing, compressive strength $\left(\sigma_{\mathrm{pk} 1}\right)$ is recovered. In the investigated strain range, in case of samples D801, D802, D601, and D602, this is manifested by the appearance of a consecutive clear peak on the stress-strain curve. In case of the sample with a porosity of $60 \%$ with the smallest elementary cell D603, along with the increasing deformation, the peaks are more difficult to distinguish, which indicates densification of the cellular lattice structure.

The fracture starts at the top surface of specimens by the formation of crush band, for which angles with the loading direction maintain a constant value $\sim 45^{\circ}$ (Fig. 10). As
Fig. 8 Diagram of the compression curve of the cellular structure with the characteristic parameters marked

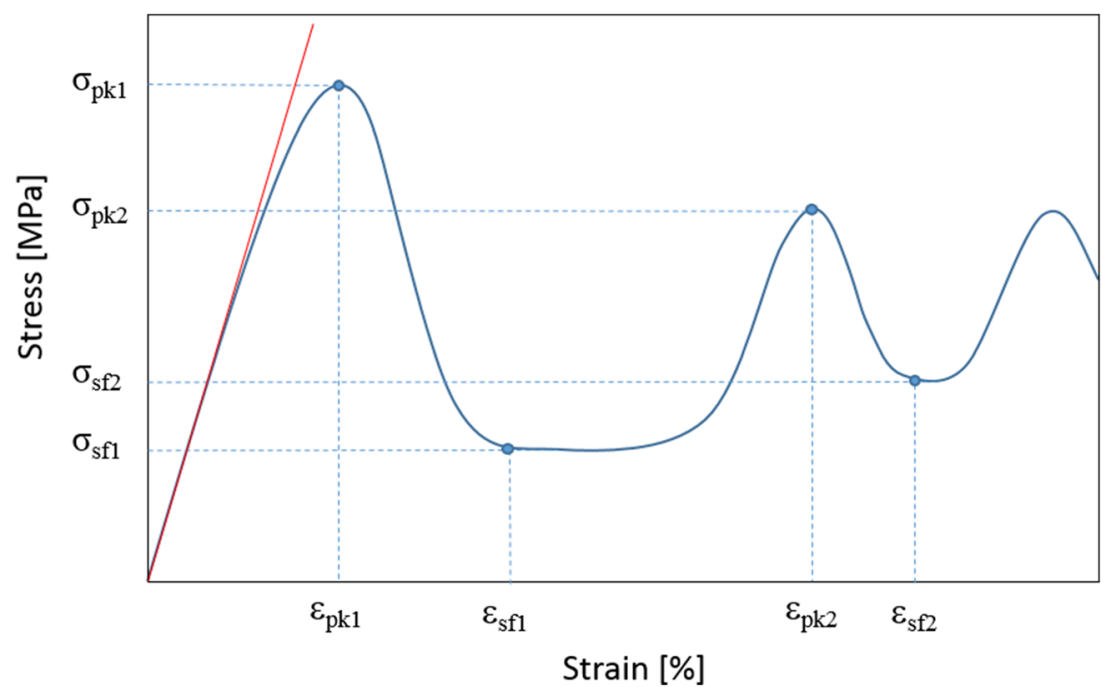


Table 5. Mechanical properties of the samples.

\begin{tabular}{lllllll}
\hline Sample & $\sigma_{\mathrm{pk} 1}(\mathrm{MPa})$ & $\sigma_{\mathrm{sfl}}(\mathrm{MPa})$ & $\varepsilon_{\mathrm{pk} 1}(\%)$ & $\varepsilon_{\mathrm{sfl}}(\%)$ & $\mathrm{E}(\mathrm{MPa})$ & $\mathrm{W}_{\mathrm{pk} 1}(\mathrm{~J})$ \\
\hline $\mathrm{D} 801$ & 62 & 4.5 & 8.4 & 16 & 3200 & 14 \\
$\mathrm{D} 802$ & 63 & 8.5 & 6.7 & 11 & 3400 & 11 \\
D803 & 59 & 20 & 4.5 & 7 & 4000 & 7.4 \\
D601 & 160 & 39 & 7.7 & 14 & 9200 & 40 \\
D602 & 170 & 50 & 6.4 & 13 & 11,000 & 37 \\
D603 & 200 & 100 & 6.3 & 7.7 & 12,000 & 29 \\
\hline
\end{tabular}

applied strain increases, the crush bands expand gradually from the top to the bottom, resulting in collapse of the specimen. Such compression reactions are compatible with their brittle character of the stress-strain curves.
In all cases, the fracture surfaces show two types of characteristic features on fracture surfaces: relatively smooth and smeared surface and dimple-like structure. Presence of dimple-like structure suggests that failure mechanism is
Fig. 9 Stress-strain curves for D601, D602, and D603 samples
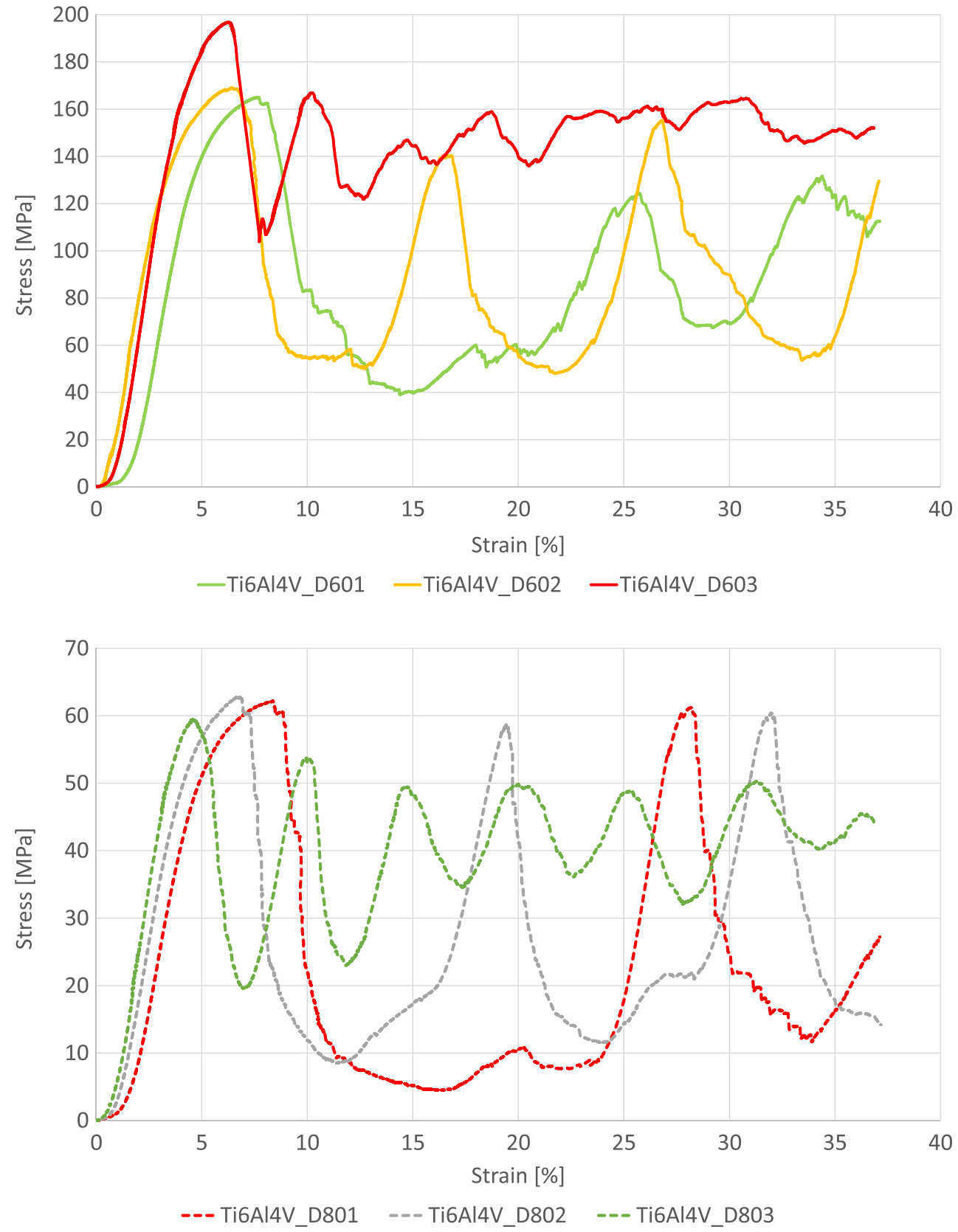
Fig. 10 Fracture surfaces of Ti6A14V D801 (a, c, e) and D601 $(\mathbf{b}, \mathbf{d}, \mathbf{f})$ diamond cellular lattice a)
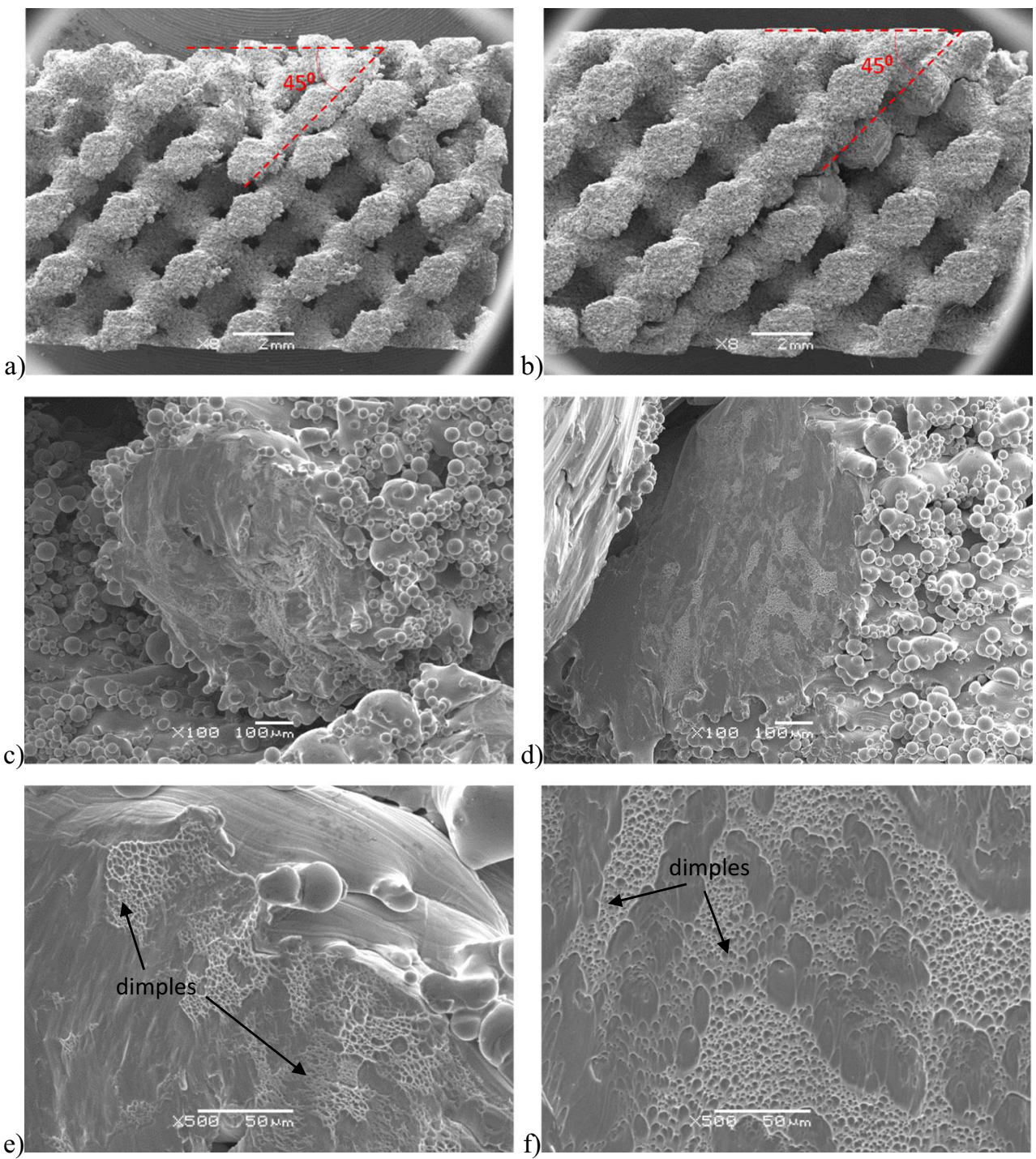

associated with large plastic deformations. The smeared surface could be a consequence of the heavy shear deformation of dimples along the direction of shear stress $[55,56]$. It can be assumed that the dimples are created along epitaxially grown elongated grains, as the authors of the work [57] also stated. Sample fractured surfaces of Ti6Al4V struts for D601 and D801 after the compression test are shown in Fig. 10.

\subsection{Prediction of the elastic response of the cellular lattice}

The reported increase in the modulus of elasticity of the samples with the biggest number of the basic unit cells was confirmed by FEA simulations. This phenomenon can be associated with the "size effect" occurring in 3D periodic cellular structures. In the experiment, boundary conditions were imposed on the upper and lower plane. The four vertical surfaces of the cube could deform freely. The individual response of elementary cells depends on their position in the three- dimensional structure. Deformation of cells inside a threedimensional structure surrounded by other cells or located near the surface where the boundary conditions have been imposed are more limited than deformation of the cells adjacent to stress-free boundaries. The increasing number of elementary cells in the structure means that those on the sides have minor influence on the overall stiffness of the system. In Fig. 11 are presented von Mises stress distributions and zdisplacement for all analyzed samples.

Obtained simulation results also indicate that the increase in modulus of elasticity depends not only on the number of elementary cells but also on the total porosity of the structure. When considering a series of samples with a total pore volume of $80 \%$, only a slight increase in the modulus of elasticity (by approx. $350 \mathrm{MPa}$ ) is noted along with the increasing number of elementary cells. For the series of samples for which the pore volume $V_{v}$ was $60 \%$, the elastic modulus increased by $2376 \mathrm{MPa}$ for the sample with the highest number of unit cells (D603). 
Fig. 11 Prediction of the elastic modulus, Von Misses stress distribution, and z-displacement of the diamond cellular structure

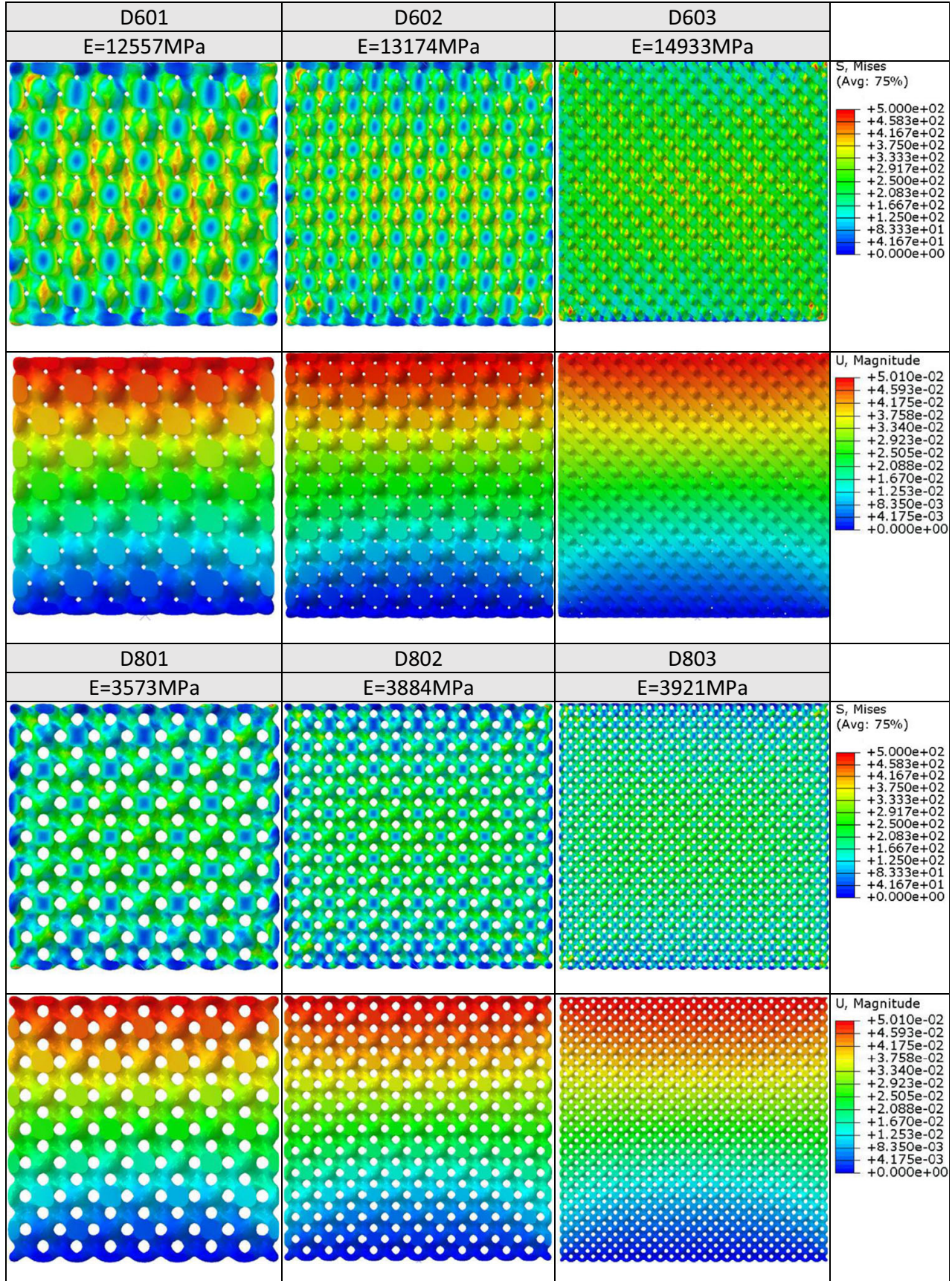

\section{Conclusion}

Basing on the presented results of performed experiments, it can be stated that applied methodology of design and manufacturing of diamond Schwarz lattice structures allows achieving components with predictable properties.

- Diamond Schwarz-type Ti6A14V cellular lattice with fixed total porosity $60 \%$ and $80 \%$ was successfully fabricated by selective laser melting. The geometry of the model was well reproduced in the entire volume of the sample.
The total volume of the defects inside solid struts of the cellular lattice did not exceed $0.2 \%$.

- Total porosity of the manufactured samples was lower on average by $4-18 \%$ in relation to the porosity of the CAD model. The largest difference was observed in the samples with the smallest elementary unit cell.

- Compression strength of diamond Schwarz type Ti6A14V cellular lattice is related primarily with the total porosity of the sample and reaches the average value $177 \mathrm{MPa}$ and $61 \mathrm{MPa}$ for $60 \%$ and $80 \%$ respectively.

- When total number of unit cell is reduced from 1728 to 64 at a fixed volume fraction of $60 \%$, the compressive 
modulus decreased from 12,000 to $9200 \mathrm{MPa}$, and the compressive strength decreased from 200 to $160 \mathrm{MPa}$.

- Failure of the diamond Schwarz-type Ti6Al4V cellular lattice is highly related to geometry of the unit cell and in consequence the stress distribution. In this case, destruction was mainly presented in the pattern of a diagonal shear band, which was confirmed by numerical simulations.

- Finite element calculations properly predict the stiffness of the sample, but in the subsequent calculations, it seems to be worth checking the influence of the internal porosity and the struts roughness on the results obtained.

Funding information This study was funded by the National Science Centre, Poland under grant number DEC-2017/01/X/ST8/00780. This research was supported in part by PLGrid Infrastructure.

Open Access This article is distributed under the terms of the Creative Commons Attribution 4.0 International License (http:// creativecommons.org/licenses/by/4.0/), which permits unrestricted use, distribution, and reproduction in any medium, provided you give appropriate credit to the original author(s) and the source, provide a link to the Creative Commons license, and indicate if changes were made.

\section{References}

1. Gibson LJ, Ashby MF (2014) Cellular solids: structure and properties, second edition. Cambridge University Press doi:https://doi.org/ $10.1017 / \mathrm{CBO} 9781139878326$

2. Degischer HP, Kriszt B (2002) Handbook of cellular metals: production, processing, applications. Wiley-VCH Verlag doi:https:// doi.org/10.1002/3527600558.fmatter indsub

3. Banhart J (2001) Manufacture, characterisation and application of cellular metals and metal foams. Prog Mater Sci 46:559-632. https://doi.org/10.1016/S0079-6425(00)00002-5

4. Davies GJ, Zhen S (1983) Metallic foams: their production, properties and applications. J Mater Sci 18:1899-1911. https://doi.org/ 10.1007/BF00554981

5. Ashby M (2006) The properties of foams and lattices. Philos Trans R Soc A Math Phys Eng Sci 364:15-30. https://doi.org/10.1098/ rsta.2005.1678

6. Banhart J (2005) Aluminium foams for lighter vehicles. Int J Veh Des 37:114. https://doi.org/10.1504/IJVD.2005.006640

7. Baumeister J, Banhart J, Weber M (1997) Aluminium foams for transport industry. Mater Des 18:217-220. https://doi.org/10.1016/ S0261-3069(97)00050-2

8. García-Moreno F (2016) Commercial applications of metal foams: their properties and production. Materials (Basel) 9:85. https://doi. org/10.3390/ma9020085

9. Xia X, Zhang Z, Zhao W et al (2017) Acoustic properties of closedcell aluminum foams with different macrostructures. J Mater Sci Technol 33:1227-1234. https://doi.org/10.1016/j.jmst.2017.07.012

10. Otaru AJ, Morvan HP, Kennedy AR (2018) Modelling and optimisation of sound absorption in replicated microcellular metals. Scr Mater 150:152-155. https://doi.org/10.1016/j.scriptamat.2018.03. 022

11. Wong M, Tsopanos S, Sutcliffe CJ, Owen I (2007) Selective laser melting of heat transfer devices. Rapid Prototyp J 13:291-297. https://doi.org/10.1108/13552540710824797
12. Yadroitsev I, Shishkovsky I, Bertrand P, Smurov I (2009) Manufacturing of fine-structured 3D porous filter elements by selective laser melting. Appl Surf Sci 255:5523-5527. https://doi.org/ 10.1016/j.apsusc.2008.07.154

13. Hollister SJ, Maddox RD, Taboas JM (2002) Optimal design and fabrication of scaffolds to mimic tissue properties and satisfy biological constraints. Biomaterials 23:4095-4103. https://doi.org/10. 1016/S0142-9612(02)00148-5

14. Zhang X-Y, Fang G, Zhou J (2017) Additively manufactured scaffolds for bone tissue engineering and the prediction of their mechanical behavior: a review. Materials (Basel) 10:50. https://doi. org/10.3390/ma10010050

15. Jetté B, Brailovski V, Dumas M et al (2018) Femoral stem incorporating a diamond cubic lattice structure: design, manufacture and testing. J Mech Behav Biomed Mater 77:58-72. https://doi.org/10. 1016/j.jmbbm.2017.08.034

16. Liu F, Zhang D, Zhang P et al (2018) Mechanical properties of optimized diamond lattice structure for bone scaffolds fabricated via selective laser melting. Materials (Basel) 11:374. https://doi. org/10.3390/ma11030374

17. Yap CY, Chua CK, Dong ZL et al (2015) Review of selective laser melting: materials and applications. Appl Phys Rev 2:041101. https://doi.org/10.1063/1.4935926

18. Guo N, Leu MC (2013) Additive manufacturing: technology, applications and research needs. Front Mech Eng 8:215-243. https:// doi.org/10.1007/s11465-013-0248-8

19. Herzog D, Seyda V, Wycisk E, Emmelmann C (2016) Additive manufacturing of metals. Acta Mater 117:371-392. https://doi. org/10.1016/j.actamat.2016.07.019

20. Frazier WE (2014) Metal additive manufacturing: a review. J Mater Eng Perform 23:1917-1928. https://doi.org/10.1007/s11665-0140958-Z

21. Sun W, Starly B, Darling A, Gomez C (2004) Computer-aided tissue engineering: application to biomimetic modelling and design of tissue scaffolds. Biotechnol Appl Biochem 39(1):49-58. https:// doi.org/10.1042/ba20030109

22. Kou ST, Tan ST (2013) An approach of irregular porous structure modeling based on subdivision and NURBS. Comput Aided Des Appl 10:355-369. https://doi.org/10.3722/cadaps.2013.355-369

23. Song G-H, Jing S-K, Zhao F-L et al (2017) Design optimization of irregular cellular structure for additive manufacturing. Chinese $\mathrm{J}$ Mech Eng 30:1184-1192. https://doi.org/10.1007/s10033-0170168-3

24. Gabbrielli R, Turner IG, Bowen CR (2007) Development of modelling methods for materials to be used as bone substitutes. Key Eng Mater 361-363:903-906. https://doi.org/10.4028/www.scientific. net/KEM.361-363.903

25. Giannitelli SM, Accoto D, Trombetta M, Rainer A (2014) Current trends in the design of scaffolds for computer-aided tissue engineering. Acta Biomater 10:580-594. https://doi.org/10.1016/j.actbio. 2013.10.024

26. Kapfer SC, Hyde ST, Mecke K et al (2011) Minimal surface scaffold designs for tissue engineering. Biomaterials 32:6875-6882. https://doi.org/10.1016/j.biomaterials.2011.06.012

27. Yoo DJ (2012) Computer-aided porous scaffold design for tissue engineering using TPMS. Int J Precis Eng Manuf 12:61-71. https:// doi.org/10.1007/s12541-012-0068-5

28. Schoen AH (1970) Infinite periodic minimal surfaces without selfintersections. Nasa Tech Note D-5541

29. Gandy PJF, Klinowski J (2000) Exact computation of the triply periodic G ('Gyroid') minimal surface. Chem Phys Lett 321:363371. https://doi.org/10.1016/S0009-2614(00)00373-0

30. Gandy PJ, Cvijović D, Mackay AL, Klinowski J (1999) Exact computation of the triply periodic D ('diamond') minimal surface. Chem Phys Lett 314:543-551. https://doi.org/10.1016/S00092614(99)01000-3 
31. Gandy PJF, Klinowski J (2000) Exact computation of the triply periodic G ('gyroid') minimal surface. Chem Phys Lett 321:363371. https://doi.org/10.1016/S0009-2614(00)00373-0

32. Gandy PJF, Bardhan S, Mackay AL, Klinowski J (2001) Nodal surface approximations to the P,G,D and I-WP triply periodic minimal surfaces. Chem Phys Lett 336:187-195. https://doi.org/10. 1016/S0009-2614(00)01418-4

33. Yoo D-J (2014) Advanced porous scaffold design using multi-void triply periodic minimal surface models with high surface area to volume ratios. Int J Precis Eng Manuf 15:1657-1666. https://doi. org/10.1007/s12541-014-0516-5

34. Papazetis G, Vosniakos G-C (2016) Direct porous structure generation of tissue engineering scaffolds for layer-based additive manufacturing. Int J Adv Manuf Technol 86:871-883. https://doi. org/10.1007/s00170-015-8237-1

35. Blanquer SBG, Werner M, Hannula M et al (2017) Surface curvature in triply-periodic minimal surface architectures as a distinct design parameter in preparing advanced tissue engineering scaffolds. Biofabrication 9:025001. https://doi.org/10.1088/17585090/aa6553

36. Wang Z, Huang C, Wang $\mathrm{J}$ et al (2019) Design and simulation of flow field for bone tissue engineering scaffold based on triply periodic minimal surface. Chinese J Mech Eng 32:19. https://doi.org/ 10.1186/s10033-019-0329-7

37. Mahmoud D, Elbestawi MA (2019) Selective laser melting of porosity graded lattice structures for bone implants. Int J Adv Manuf Technol 100:2915-2927. https://doi.org/10.1007/s00170-0182886-9

38. Zaharin H, Abdul Rani A, Azam F et al (2018) Effect of unit cell type and pore size on porosity and mechanical behavior of additively manufactured Ti6A14V scaffolds. Materials (Basel) 11:2402. https://doi.org/10.3390/ma11122402

39. Yan C, Hao L, Hussein A, Young P (2015) Ti-6Al-4V triply periodic minimal surface structures for bone implants fabricated via selective laser melting. J Mech Behav Biomed Mater 51:61-73. https://doi.org/10.1016/j.jmbbm.2015.06.024

40. Kadkhodapour J, Montazerian H, Darabi AC et al (2017) The relationships between deformation mechanisms and mechanical properties of additively manufactured porous biomaterials. J Mech Behav Biomed Mater 70:28-42. https://doi.org/10.1016/j.jmbbm. 2016.09.018

41. Yan C, Hao L, Hussein A et al (2017) Microstructural and surface modifications and hydroxyapatite coating of Ti-6Al-4V triply periodic minimal surface lattices fabricated by selective laser melting. Mater Sci Eng C 75:1515-1524. https://doi.org/10.1016/j.msec. 2017.03.066

42. Spierings AB, Voegtlin M, Bauer T, Wegener K (2016) Powder flowability characterisation methodology for powder-bed-based metal additive manufacturing. Prog Addit Manuf 1:9-20. https:// doi.org/10.1007/s40964-015-0001-4

43. T Luhmann, S Robson, S Kyle, I. H. (2011). Close range photogrammetry; principles, techniques and applications. Whittles Publishing

44. Choy SY, Sun C-N, Leong KF, Wei J (2017) Compressive properties of Ti-6Al-4V lattice structures fabricated by selective laser melting: design, orientation and density. Addit Manuf 16:213224. https://doi.org/10.1016/j.addma.2017.06.012

45. International Standard (2011) ISO 13314 - Mechanical testing of metals, ductility testing, compression test for porous and cellular metals ISO 13314:2011

46. Das S (2003) Physical aspects of process control in selective laser sintering of metals. Adv Eng Mater 5:701-711. https://doi.org/10. 1002/adem.200310099

47. Murr LE, Quinones SA, Gaytan SM et al (2009) Microstructure and mechanical behavior of $\mathrm{Ti}-6 \mathrm{Al}-4 \mathrm{~V}$ produced by rapid-layer manufacturing, for biomedical applications. J Mech Behav Biomed Mater 2:20-32. https://doi.org/10.1016/j.jmbbm.2008.05. 004

47. Yang J, Yu H, Yin J et al (2016) Formation and control of martensite in Ti-6Al-4V alloy produced by selective laser melting. Mater Des 108:308-318. https://doi.org/10.1016/j.matdes.2016.06.117

49. Thijs L, Verhaeghe F, Craeghs T et al (2010) A study of the microstructural evolution during selective laser melting of Ti-6Al-4V. Acta Mater 58:3303-3312. https://doi.org/10.1016/j.actamat.2010. 02.004

50. Yan C, Hao L, Hussein A, Raymont D (2012) Evaluations of cellular lattice structures manufactured using selective laser melting. Int J Mach Tools Manuf 62:32-38. https://doi.org/10.1016/j. ijmachtools.2012.06.002

51. Maszybrocka J, Stwora A, Gapiński B et al (2017) Morphology and surface topography of Ti6A14V lattice structure fabricated by selective laser sintering. Bull Polish Acad Sci Tech Sci 65:85-92. https:// doi.org/10.1515/bpasts-2017-0011

52. Hernández-Nava E, Tammas-Williams S, Smith C et al (2017) Xray tomography characterisation of lattice structures processed by selective electron beam melting. Metals (Basel) 7:300. https://doi. org $/ 10.3390 /$ met7080300

53. Bauereiß A, Scharowsky T, Körner C (2014) Defect generation and propagation mechanism during additive manufacturing by selective beam melting. J Mater Process Technol 214:2522-2528. https://doi. org/10.1016/j.jmatprotec.2014.05.002

54. Gong H, Rafi K, Gu H et al (2014) Analysis of defect generation in Ti-6Al-4V parts made using powder bed fusion additive manufacturing processes. Addit Manuf 1-4:87-98. https://doi.org/ 10.1016/j.addma.2014.08.002

54. $\mathrm{Xu} \mathrm{Z,} \mathrm{He} \mathrm{X,} \mathrm{Hu} \mathrm{H} \mathrm{et} \mathrm{al} \mathrm{(2019)} \mathrm{Plastic} \mathrm{behavior} \mathrm{and} \mathrm{failure} \mathrm{mech-}$ anism of Ti-6Al-4V under quasi-static and dynamic shear loading. Int J Impact Eng 130:281-291. https://doi.org/10.1016/j.ijimpeng. 2019.04.008

56. Mazur M, Leary M, Sun S et al (2015) Deformation and failure behaviour of Ti-6Al-4V lattice structures manufactured by selective laser melting (SLM). Int J Adv Manuf Technol. https://doi.org/10. 1007/s00170-015-7655-4

57. Wang T, Zhu YY, Zhang SQ et al (2015) Grain morphology evolution behavior of titanium alloy components during laser melting deposition additive manufacturing. J Alloys Compd 632:505-513. https://doi.org/10.1016/j.jallcom.2015.01.256

Publisher's note Springer Nature remains neutral with regard to jurisdictional claims in published maps and institutional affiliations. 